\title{
Considering our genetic legacy
}

\author{
Bartha Maria Knoppers
}

Engineering the Human Germline: An Exploration of the Science and Ethics of Altering the Genes We Pass to Our Children

\section{Edited by Gregory Stock and John Campbell 2000 Oxford University Press, 192 pages, \$29.95 hardcover}

"Technology has now advanced to the point where the unthinkable needs to be carefully examined." So begins the preface of this fascinating, lively, and frank analysis of germline genetic manipulations of reproductive cellsmanipulations that can alter both the immediate patient and his or her descendants.

"Examining the unthinkable" at a symposium in March 1998, this book fascinates by virtue of the fact that it constitutes one of the first in-depth analyses of the realistic possibilities and problems of this technology. The first part is replete with solid academicians (Leroy Hood, French Anderson, Mario Capecchi, Daniel Koshland, Michael Rose, and Lee Silver) who lay the groundwork for a better understanding of "genetic engineering." Distinguishing between somatic enhancement and germline therapies, the possibility of meaningful human

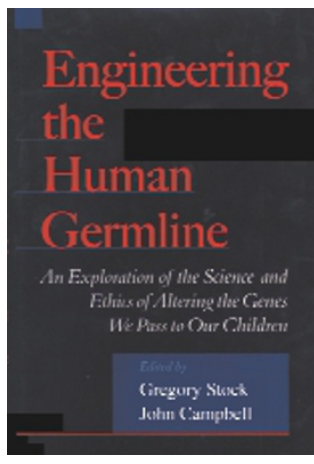

ly European position of outright prohibition of germline engineering without qualification.

Most importantly, the discussion throughout is frank and open. Faced with a climate of fear-mongering encouraged by the popular media and by "genohype," the last part of the book contains a collection of personal views in the form of short essays. Included are the voices of theologians, ethicists, and publicpolicy makers. These are structured around four questions of opinion on the legitimacy, dangers, and need for international policy on germline engineering. It is of note that the fourth question forces the issue by asking each contributor about the possibility for their own children. Ranging from condemnations of a static view of nature, of "DNA über alles," of the attribution of human dignity to contingent future persons, of titillating science fiction, to that of life as a positive value in and of itself, or finally, to a call for an ecosystem approach, the breadth and the strength of these voices is a clear demonstration of why such discussion is urgently needed. Too often cowed by facile and unnuanced proclamations of the "unnatural," or of "hubris"- to say nothing of personal threats to one's safety for even discussing the issue-this refreshdesign is approached in an extremely clear and understandable way for nonscientists. No uniformity of approach or ideas emerges, a true reflection of the controversial nature but also of the scientific uncertainty still surrounding this technology.

The second part of the book is livelier, its debate format slipping out of the arena of typical "pros and cons" arguments to reveal the personal insights and values of the aforementioned, together with panelists such as James Watson, John Fletcher, and Andrea Bonnicksen. Hood and Watson would maintain that "science proceeds and succeeds by doing." Yet Anderson, perhaps scarred by his experience of presenting the less controversial somatic gene therapy to over 15 committees for approval, is extremely cautious and hesitant regarding germline technology. Bonnicksen presents, among others, the large-

Bartha Maria Knoppers is professor of law at the University of Montreal and chair of the Human Genome Organization (HUGO) ethics committee(knoppers@droit.umontreal.ca). ing and honest look at the very complex scientific and socioethical issues surrounding germline intervention should be applauded.

In short, the epigenetic and dynamic exploration of the science and ethics of altering the genes we pass to our children should be required reading for any future public fora or for a priori public-policy proclamations, especially now that "scientists and medics have replaced priests" (Mauron, p. 118). Irrespective of the truth of this last assertion, a solely person-centered perspective to include a gene pool (at the level of humanity)-centered perspective. The human genome alone is not the "inner sanctum of humanness" ( $\mathrm{p}$. 118). Genomes are not people and technologies per se are not good or bad. The ethical evaluation of the purposes and implications of germline engineering lies in the careful, cautious, and courageous discernment of its purposes and implications as found in this book.

The true challenge is in the responsible use of this potential power over the germline in our decision making. But there is no doubt that decisions need to be made. there is no doubt that we need to move beyond 